\title{
AULRE 2020: RE Matters
}

\section{Guest Editors' Introduction}

\author{
Sean Whittle ${ }^{1} \cdot$ Stephen J. McKinney ${ }^{2}$
}

Accepted: 23 September 2020 / Published online: 12 October 2020

(c) Australian Catholic University 2020

The great lockdown of 2020 caused many events and gatherings to be cancelled in the wake of the Covid-19 pandemic, including the AULRE 2020 Annual Conference. The Association of University Lecturers of Religious Education (AULRE) is a network for learning, teaching and research in religion and education.

It is with great pleasure that we present a representative sample of papers that were planned for our conference through this Special Edition of the Journal of Religious Education (JRE). When preparing for the conference we deliberately chose a title that was wide ranging and it is used for this special edition: AULRE 2020: RE Matters. The nine articles presented here reflect the differing ways in which this theme can be understood. From impassioned reflections on the reasons why RE still matters as an important part of the school curriculum, to a range of matters or issues which are currently impacting on different aspects of Religious Education in one part of the world particularly in relation to the Commission on Religious Education's Final Report. Taken together, the articles in this special edition provide a fascinating snapshot into the areas of active research and interest concerning RE in the UK. As such they stand as highly appropriate ways of embodying what would have been another important and successful annual conference.

The AULRE annual conference has become an increasingly important focal point for those of us in the UK (and beyond) who are involved with RE teacher education/training and research in the field of Religious Education. It provides us with an opportunity to collaborate and progress our research together. In recent years it has been necessary to expand the provision for presenting short papers at the conference to provide suitable space for over 50 presentations which have been selected by the conference committeealongside high-quality keynote addresses. Despite the precarious times for Religious Education in the UK, there is a committed and strong research community working on projects which are of international and national significance. The AULRE 2020 conference was scheduled to take place in May 2020 at Newman University, Birmingham. In this special edition two of the planned three keynotes are presented, from Dr Janet Orchard and

Sean Whittle

sean.whittle@stmarys.ac.uk

Stephen J. McKinney

Stephen.mckinney@glasgow.ac.uk

1 Vice-chair of AULRE, London, UK

2 Chair of AULRE, Glasgow, UK 
Dr Emma Salter. The other articles were originally submitted as short papers and we are grateful to the authors for their work and time in developing these into high quality articles. The nine papers are indicative of the quality we have come to expect at the AULRE annual conferences. In selecting the papers for this special edition, as well as preparing for the conference, the AULRE executive have played a pivotal role. We offer particular thanks to our review panel, especially Dr Emma Salter and Dr Linda Whitworth.

The first paper, by Dr Janet Orchard, puts an intriguing spin on the theme, by engaging with the loaded question of whether or not RE still matters? Dr Orchard gives an affirmative answer by drawing on an argument framed by an established philosophical discussion of reasons for compulsory RE in schools. These reasons are considered in turn, with particular reference to the RE curriculum in both England and South Africa, understanding that general principles need to be applied in specific cases. One justification-based on socialisation or acculturation-remains the most politically compelling argument for RE in community schools, connected with promoting 'religious literacy' through the subject. Whether or not this link exists and how it might be promoted in practice remain in some doubt. This leads Dr Orchard to question whether having one specific aim for RE is either necessary or desirable as has been suggested, given how well other potentially justifiable reasons can be seen to inter-relate. Dr Orchard is relatively pessimistic for the future of non-elective RE in English community schools where no-one is able to champion the subject effectively. The future looks brighter in faith-based contexts, which might include 'religiously vibrant' South Africa, once the relationship between religious and political literacy is clearly identified. She argues that RE for all does still matter very much, as an entitlement which may contribute to the flourishing of many children and young people where it is taught well and adequately resourced.

The second paper, by Dr Emma Salter notices that faith-practitioners' involvement, as visiting speakers or study-visit hosts, is a recommended teaching strategy in secular RE. It examines problems of authentic representation of religious traditions in secular RE and evaluates the extent to which faith-practitioners' involvement as a learning strategy can address authentic representation of religions as a learning principle. Original data for the paper is drawn from four qualitative interviews with faith-practitioners from different Christian denominations about their preferred representations of Christianity during study-visits to their churches as part of the secular RE programme. The paper finds that the preferred representations of the faith-practitioners can be categorised as insiderinstitutional (denominational) and insider-personal. Together, these types of representation can complement authenticity in the representation of religions in RE because they offer particular, rather than generalised, accounts of religious traditions.

The third paper, composed by Professor Robert Bowie, reports for the first time, a seed corn pilot study that presents a moment of the collective consciousness of an RE department in the midst of curriculum change. It records their concerns about the impact of increased content on depth in a new exam course, and the particular consequence this has for the kind of learning that happens around texts. It reveals concerns about the representation of religion in the curriculum and the distance between that representation and teachers' perceptions of pupils' spiritual and religious lives. It also identifies teachers' sense of fear and guilt about the challenge of fulfilling their duties to pupils, the secular authorities and the Catholic authorities, and reveals insights around the question of science and religion. In this single focus group, the collective consciousness of an RE department captures many key issues of significance in RE today.

The fourth article, by Professor Stephen McKinney, homes in on the educational impact of the 2020 global pandemic. Covid-19 and the subsequent worldwide 
lockdowns have had a major impact on families and school education. The lockdowns have highlighted and exacerbated the disadvantages experienced by those children who suffer from child poverty. This article focuses on food insecurity and the digital divide, or digital exclusion, and argues that these have emerged as even more pressing issues during lockdowns for children suffering from child poverty. The article provides an outline of the response of the Catholic Church and Catholic schools, primarily in the United Kingdom, and argues that for those children who experience digital exclusion, this is effectively exclusion from the religious education, religious life, community and the pastoral and spiritual support that is normally offered by the Catholic school.

In the fifth contribution, Dr Ruth Flanagan subjects the concept of worldviews to critical scrutiny. The article explains how the term 'worldviews' is employed across disciplinary boundaries, yet with no agreed definition it may actually obscure rather than clarify meaning. The use of the term has grown in frequency, particularly in RE in England, since the Final Report (2018) of the Commission on Religious Education which recommended changing the name of RE to 'Religion and Worldviews'. Response to the report has been mixed. Some fear that an introduction of worldviews may lead to a dilution of RE and overburden an already overstretched teaching profession; others welcome a meaningful study of non-religious worldviews which they view as more pertinent in the current growth of those who adhere to 'no faith'. Ultimately, teaching worldviews raises questions of selection: are all worldviews equally appropriate for pupils to study and consistent with the aims of education? For example, is it appropriate for a 6-year-old to study Hedonism or National Socialism? This paper problematises the binary nature of the debate and interrogates the usage of the term 'worldviews'. Rather than consider worldviews as a discrete body of knowledge that imposes on an already overburdened curriculum, she proposes that employing worldviews as an overarching concept and providing a type of paradigmatic analysis for RE may lead to a greater and more profound understanding of religion(s).

The sixth paper maintains the focus on issues triggered off by the commission on Religious Education. Dr Linda Whitworth reviews the recommendations in the Final Report for at least twelve hours of RE for 'all forms of primary Initial Teacher Education' (CORE 2018, p. 15), challenging the current provision of many primary ITE providers. Information gathered by the National Association of Teachers of Religious Education (NATRE 2018) and others demonstrates the need to improve not only the hours taught, but also the quality of provision across all training routes. Many beginner teachers lack confidence in their subject knowledge of RE and fear causing offence (NATRE 2018; Whitworth 2017). If RE is to play a valid part in a twenty-first century primary curriculum, teacher education and development need to address these concerns and develop a deeper knowledge and understanding of the subject. This paper explores aspects of knowledge in RE, the importance of developing pedagogies in response to knowledge and considers a project which responds directly to the Commission's report.

Another paper engaging with the Commission on Religious Education is by Dr Sean Whittle, which offers an evaluation of the Catholic response to the Final Report. The reasons why such a significant education provider might take a hesitant stance to the findings of the CoRE is deeply intriguing and stands in need of careful scrutiny. After offering a brief overview of both the importance and content of the Final Report, a summary of the Catholic response to it will be presented. Then the paper offers an analysis and some likely explanations for the form and content of this response. Finally, Dr Whittle argues that on theological and ethical grounds a far more positive and 
detailed response could have been offered to the Final Report in order to help bring about the much-needed recommendations that the CoRE called for.

In the eighth paper in this AULRE special edition, Dr Matthew Vince focuses on the issue of how Muslim RE teachers manage their identities in relation to being neutral. Beginning with the longstanding criticism of the whiteness of the professional discourses in teaching, the paper draws attention to Bariso's (2001) analysis that where whiteness is constructed as being professional then blackness is constructed as unprofessional, in turn excluding blackness from the construction of the teacher. Similarly, Bhopal (2015) argues that this presents a clash between embodying blackness and embodying the teacher. With the turn to research surrounding Muslim teachers, attributes of Muslimness have also been shown to be a source of marginalisation within school contexts (Shah 2016). Accordingly, in this paper Dr Vince explores how 'Muslim RE teachers' characterise 'becoming neutral' as the formative part of becoming an RE teacher. However, this was particularly challenging due to the hypervisibility of their Muslimness, particularly for female Muslim teachers. These challenges are then framed as an issue of whiteness, disproportionally affecting those who do not fit the white teacher norm. The conclusion of the paper is an argument for the pressing need to change how 'neutrality' is understood.

In the final paper in this AULRE special edition, Dr Pat Hannam and Dr Farid Panjwani address concerns regarding documented increases in xenophobia in the UK and more widely around the world. This is evidenced by a rise in religiously motivated hate crimes, especially against Muslims and Jews. Their enquiry is into the potential religious education has to mitigate xenophobia and whether there is an educational justification for it to do so.

Dr Hannam and Dr Panjwani suggest that a religious education that seeks to mitigate xenophobia will need teachers who themselves take plurality seriously. This means not only appreciating that there is a great deal to know in terms of history and in terms of beliefs and practices, but also that a religious life must be considered existentially. This paper concludes by making the point that religious education is uniquely placed to bring humanity to the heart of education, in light of its close connection to human experience, and, in doing so, to mitigate the effects of xenophobia. This is a timely paper, because there is a need to alert the religious education community to the significance of doing this at this time, and the danger of ignoring it, for the continued well-being of the public sphere itself.

AULRE is very grateful to the JRE Editor-in-Chief, Professor Peta Goldburg, for the invitation to present this special edition. We would also like to thank the journal administrator Jenni Woodward for her practical help and guidance in bringing this edition to fruition.

Four articles not related to the AULRE conference are also included in this edition. These articles are representative of Religious Education in Germany, Northern Ireland and the United States of America. The fourth article addresses Religious Education within the Maronite Church.

Publisher's Note Springer Nature remains neutral with regard to jurisdictional claims in published maps and institutional affiliations. 